\title{
Fashion Industry as a Big Data Enterprise for Sustainability
}

\author{
Paolo Tamborrini ${ }^{1}$, Chiara L Remondino ${ }^{1 *}$, Cristina Marino $^{1}$ \\ Department of Architecture and Design - Politecnico di Torino
}

Submission: March 06, 2018; Published: March 14, 2018

*Corresponding author: Chiara L Remondino, Department of Architecture and Design, Politecnico di Torino, Turin, Italy, Tel: +39 0110908866; Email: chiara.remondino@polito.it

\begin{abstract}
Fashion has the power to tell over the years human stories and cultural changes: every day through clothes we can communicate who we are and who we want to be.

This research aims to explore this sector as a complex system trying to understand the relationship between places, purchase and actors involved. Starting from data analysis and exploration by industries, brands, territories and consumers, this contribution shows how a big dataoriented culture can be useful to design new products, services and process with a new perspective throwing the bases for an innovative and sustainable fashion industry.
\end{abstract}

Keywords: Fashion industry; Data; Sustainability; Systemic innovation design

\section{Introduction}

Fashion is the industry with the most intrinsic social nature: it has all the potentialities and the resources required to re-design our cultural paradigms from the current to a more hopeful and sustainable one. Fashion system drivers have always been designed for speed and convenience. Mechanization and mass production have escalated into the manufacture of cheap; disposable clothing has become all too common. Problems related to fashion production increased throughout the 20th century creating deeper roots that have blocked the system in a state of unsustainability [1]. Nevertheless, the fashion industry is highly fragmented, with thousands of actors involved, one of the most complex global production networks and supply chains, and a vision that results someway difficult to understand [2].

The research aims to analyze the fashion industry as a datadriven enterprise. The continuing rise in the importance and challenges of big data, indeed, is one of the most important features of contemporary economy and society.

The need of a big data-oriented culture is becoming essential leading on one side to re-design the organization structure, and on the other side to perceive them as a complex system comprehensible only through data and the strength between their relations and functions, focusing on innovation and sustainability [3].
The correlation of data characterized by greater information power and higher quality gives the chance to make more informed decisions that lead to undertaking better and more sustainable actions, with consequent impact on the strategic vision not only at the organizational level but also speaking about consciousness. Concerning sustainability, indeed, data produced become tools for reading the context, quantifying its sustainable and unsustainable aspects. The research and the analysis of such informative asset are fundamental to understand better what may be the plan of action to improve environmental, economic and social sustainability, also creating products and service more human-centered.

\section{Methodology}

Today, the lack of information in fashion industries is a wide question that concerns the whole process, and all actors involved. Integrating data into fashion system can fill this gap creating new forms of value as well as a source of innovation and new services driving this sector towards key sustainability challenges.

Identify the relation between components and different elements of a complex system guaranteeing horizontal communication, flexibility, focus on innovation, human-centered 
experiences and, the personal expression for the achievement of the set goals, it's the first step to enable a more conscious and transparent decision making with a perspective of sustainability.

For the research, we applying the Systemic Innovation Design Methodology which focuses on designing relationships between people and activities to enhance knowledge and understanding about the system, to produce functions, objects, and process for the wellbeing both the individual and the collectivity $[4,5]$. Starting from a system that sees a set of data conveniently selected, organized, matched and measured on a quantitative level as an input, it appears the importance of a more qualitative output; this output can find the answer in the visual representation of the system itself.

\section{Fashion industry as a data-driven enterprise}

The need for a systemic change includes a vision of the fashion system completely different from what we used to and we tell up in this article. Unfortunately, this concept does not represent the majority of fashion products which usually are in no way linked to a value different from that of appearing and having little or nothing to do with the wellbeing of people and the collectivity.

We chose to undertake the planning process linked to change through information flows strategy, allowing the whole system to be aware of their role and to make the flow of information functional to the objectives of environmental sustainability.

Acting regarding information flow from a systemic design perspective does not represent a parametric adjustment, nor a reinforcement or a weakening of an existing cycle; it is the generation of a new cycle, that of information, in a place where it was not previously given, therefore inducing a different behavior in people. Adding or restoring data in a fashion system where the information circulation it is sometimes not linked to ethical and social value, it can, therefore, represent a powerful intervention, usually easier and cheaper than reconstructing physical infrastructures.

The structure of information flow can be a useful leverage point in the fashion system, if the information is delivered where it was not before, causing people to change behavior. However, to trigger action, it is necessary to couple new information with resources and incentives to support the behavior change [6]. In the fashion industry, adding to or changing the flow of information between companies in a supply chain or between retailers, designers and consumers can create significant changes for little effort [7].

\section{Data in fashion industry}

In the last decades, we became from the lack of data to have huge quantities of them, right now data grow in every single context and every single sector. Data are the basis of many strategic or commercial decisions, which makes them a completely flexible, dynamic and complex subject, which can be catalogued and organized in various subsets, making it necessary to continuously update the different categories of data that can be collected and used [8].

Within the framework of this research, we refer to data, and subsequently to other technological aspects, to define the tools through which to analyze, understand, simplify and visualize complex phenomena, as in this case the fashion system. Data are the necessary tool to portray the reality of the phenomenon, even if they will never be able to represent its nature as an absolute truth: they are the means that leads us to the end. Working with data in the fashion industry means reporting the intangibility of shopping and consumption experience, bus also the tangibility of the dress and the people who produce it, sell it and eventually wear it (Figure 1).
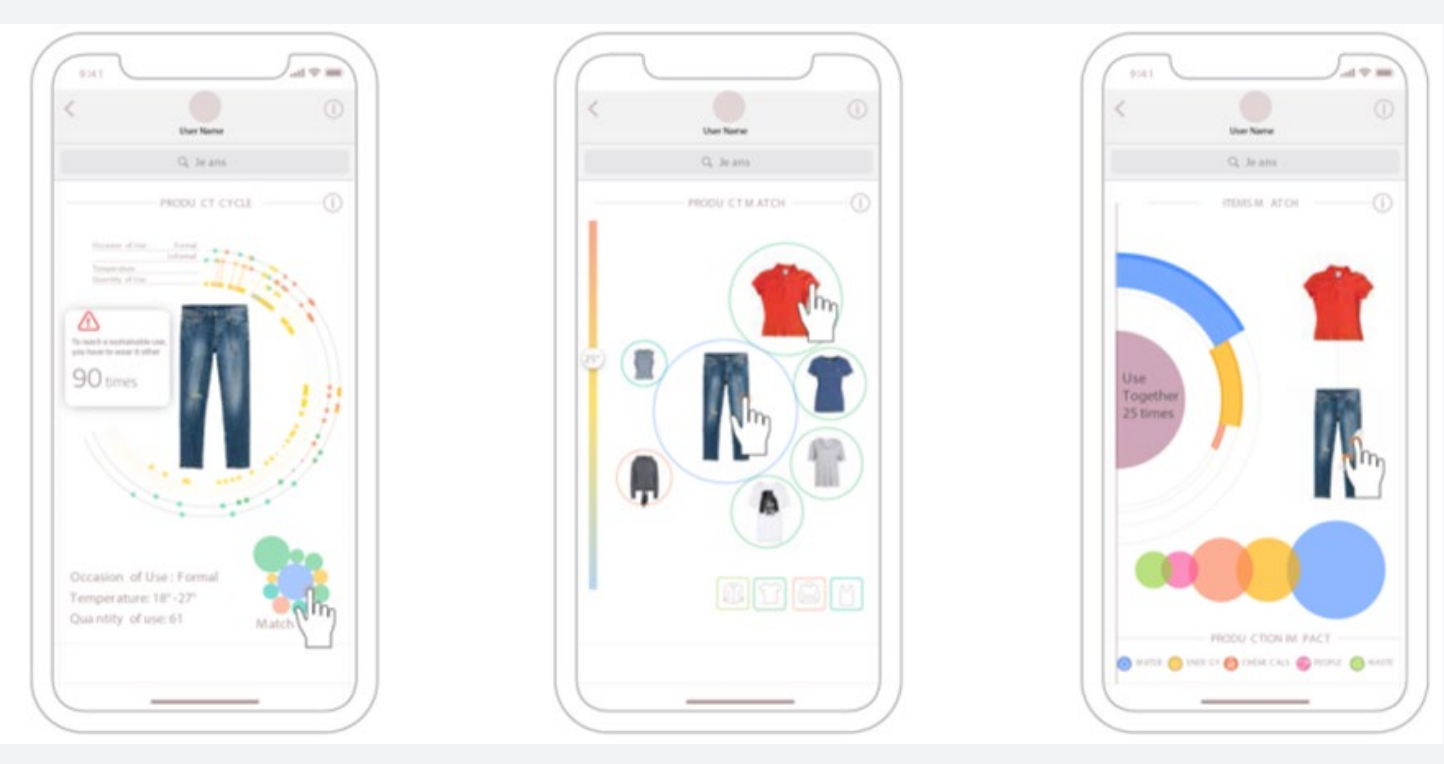

Figure 1: Example of feasible visual tool starting from the gathering and relation of consumer's data. 
Data in the fashion industry have the fundamental characteristic of being predictive and are mainly linked to two aspects: the quantitative one, defining the sales number, and the qualitative one, revealing shape, colour and material. However, it is often forgotten that data used in fashion, or tried to used as trend forecasting, are generated by people and the interactions they have with their clothes and more generally with their lifestyle. We are living in a world where personal data is unconsciously being collected every second. It is no secret that large media companies use these data to build targeted advertising algorithms and personalize the user experience in ways like curating social media feeds. Our data are everywhere: there are online accounts that we signed up with Google and Facebook and that make the user connected, so revealing our private information.

When we share our data, we can provide our experience in the field of clothing; it is clear how the study of our behavior can reveal, both to ourselves and to those who conceive, produce and distribute our clothes a whole new range of possibilities. Data we unconsciously provide to companies, already say a lot about us. However, the creation of this dataset requires the generation of information useful not only for companies, but that should also be circulated, being useful for the user, in his purchasing and consuming experience, and even to the development of products designed to be more empathetic with the consumer to extend their life.

Today that is a lot of technologies that allow gathering, organizing, and exploring different kind of data. Technologies that extend from body shape mapping to consumer needs analysis, until the open data potentialities.

Being aware of the physical characteristics of consumers is not new: through sales data, companies can manage and optimize the flow of sizes in the warehouse. However, as Fashion-Tech journalist Lorraine Sanders says: "There are really fascinating things that happen with the mapping of human bodies and the attempt to create a predictable sizing through the use of big data could help many sectors - and almost certainly could help the fashion industry". The new body sizing and scanning technologies, the intelligent scales and all the wearables can create a significant data pool for this sector; through these data, companies can create garments perfectly adapted to the needs of their customers eliminating the modification conjectures. The result may be a data-driven service that combines the best aspects of traditional retail and e-commerce stores into a highly personalized fashion experience.

The creation of the dataset, however, does not have the objective of mapping the needs of consumers to create perfect sales for companies but has the ultimate goal of gender a closer relationship between consumer and product to lengthen the life cycle. The collection of wardrobe data, therefore, has the potential to show to the consumer an overview that gives a snapshot of his current relationship with his clothes, to prevent "errors" and lengthen the life of his clothes. One of the experiments from which the creation of the dataset takes its cue involves, for example, the installation of a system that allows identifying the garments tested in the dressing room to understand the movement and the selection criteria better. Indeed, the possibility of knowing which items are not purchased makes it possible to reason in a more systemic way on the processes of fashion, on the arrangement of goods in the store, but also on the design during production and on possible future developments of textile material.

Data that the RFID technology allows to generate are new both for fashion and, in particular, for retail. Learning to make it treasure, also and above all in terms of environmental sustainability is one of the key points of this research. A recent survey by the World Economic Forum [9] reveals that $92.1 \%$ of business leaders believe that $10 \%$ of people will wear clothes connected to the Internet by 2025 . It means that we will be able to generate data that can even go beyond the management of the production process, beyond the mapping of the products in the closet. In this scenario, we will be in a position to map, under the strict control of the privacy rules, the whole experience of use and consumption of fashion items.

The fashion industry as for every aspect of our life is closely linked to open data, and these prove to be very useful to create awareness of the environmental impacts of their clothes for consumers. Including open data allows to have a global view of the movements of stock, but certainly, the potential of being able to bring the awareness of the appearance of localism linked to clothes is not to be excluded. Bringing a local agenda to bear on the fashion sector to promote sustainability is a potentially transformative process aimed at fostering economic resilience and also promoting cultural and aesthetic diversity [10].

Collecting open data about territorial behaviors is important mostly for this reason, for guiding the decision makers to the value of the customer connected to the value of his choice. By its nature, local design is rich and diverse, for it emerges through the skills and resources of a particular region, its histories, and the attitudes of its people, their traditions, social structures and markets that may or may not be available. Open data in this transversal and inclusive data collection allows companies to access to this kind of information.

\section{Conclusion}

For fashion companies, the huge amount of data in circulation allows to explore numbers on a more qualitative level, looking for insight, analyzing behaviors and reflections, to offer answers that are always closer to the real needs of contexts and of the people who live there.

Innovation and change, combined with the enormous potential of data, can start from any one of the different stages of the supply chain: the cultivation and extraction of the textile fibre, the life cycle of the product, its uses and, disposal. 
The road to sustainability is not linear, to address key future environmental challenges, we need to explore change drivers. The future of data science can help fashion to find the way to merge the technological features of the sector and the human factor of the people who fuel this industry.

A lack of information is a dangerous problem in each sector but in this one, it means that we are losing human capital with no diffusion of the right knowledge. By integrating data into fashion, we create an alternative, more awareness grounded. Data are no longer considered a static asset whose use ends when the purpose for which they were collected has been accomplished: a raw material, a vital input that can be used to create new forms of value as well as a source of innovation and new services.

\section{References}

1. Brown S, Smithsonian Institution (2012) Fashion: The Definitive History of Costume and Style. DK Publishing, New York, USA, pp. 480.

2. Farley JG, Hill C (2015) Sustainable fashion: Past, Present and Future. Bloomsbury, London, UK, pp. 237.

This work is licensed under Creative

Commons Attribution 4.0 Licens

DOI: 10.19080/CTFTTE.2018.03.555616
3. Viktor MS, Kenneth C (2013) Big data: A revolution that will transform how we live, work, and think. Houghton Mifflin Harcourt, Boston, USA, pp. 242.

4. Bistagnino L (2011) Design sistemico: progettare la sostenibilità produttiva e ambientale. Slow Food, Bra, IT, pp. 310.

5. Bistagnino L (2017) Micro Macro: The whole of micro systemic relations generates the new economic- productive model. Edizioni Ambiente, Milano, IT, pp. 350.

6. Meadows DH (2008) Thinking in Systems: A Primer. Chelsea Green Publishing, White River Junction, VT, pp. 222.

7. Fletcher K (2008) Sustainable fashion and textiles: design journeys. Earth scan, London, UK, pp. 239.

8. Bernard M (2015) Big Data Using Smart Big Data, Analytics and Metrics To Make Better Decisions and Improve Performance. John Wiley \& Sons, Hoboken, USA, pp. 256.

9. World Economic Forum (2015) Deep Shift: 21 Ways Software Will Transform Global Society.

10. Fletcher K, Grose L (2011) Fashion and Sustainability: Design for Change. Laurence King Publishing, London, UK, pp. 192.

\section{Your next submission with Juniper Publishers} will reach you the below assets

- Quality Editorial service

- Swift Peer Review

- Reprints availability

- E-prints Service

- Manuscript Podcast for convenient understanding

- Global attainment for your research

- Manuscript accessibility in different formats

( Pdf, E-pub, Full Text, Audio)

- Unceasing customer service

Track the below URL for one-step submission https://juniperpublishers.com/online-submission.php 